\title{
جذور إقصاء الآخر في العقل العربيفي ضوء الثعر الجاهلي والمرويات التاريخية
}

أ.د. كاظم حمد محراث / جامعة واسط / كلية التربية / قسم اللغة العربية

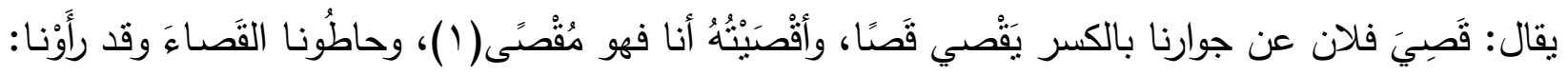

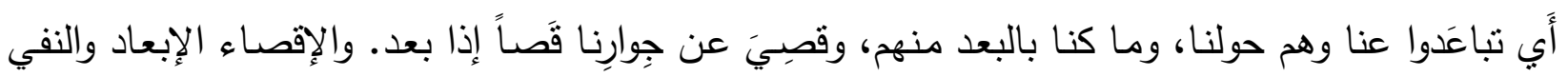

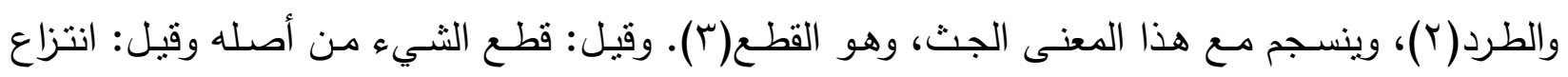

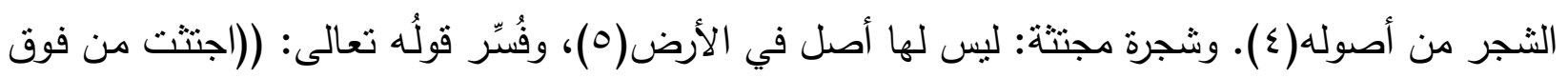

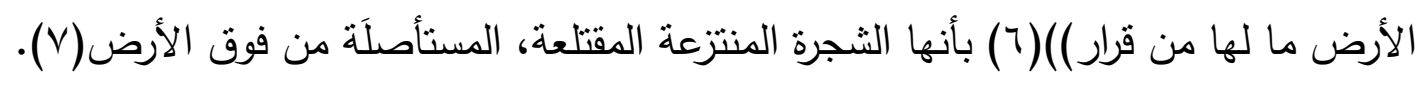

أما الدلالة الاصطلاحية للفظ الإقصاء فلا يبعد عن المعنى اللغوي: فهو الخلع والنفي والطرد من القبيلة أو الوطن أو العمل، ومحاولة إقصاء الآخر بشتى الوسائل المتاحة إرضاءً للذات الفردية أو المجتمعية، ويخضع الأهي استئصال الآخر في كثير من الأحيان لكثير من أسباب الثأر .

وسلوك التباغض والعداء بين أسلافنا في الجاهلية كان نتاج ظروف طبيعية واقتصادية واجتماعية، ألمّت

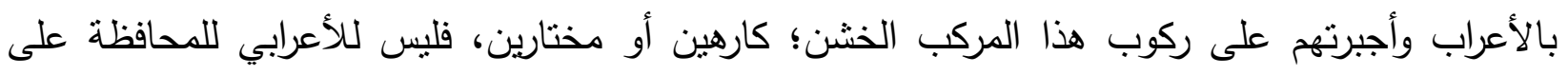
حياته ولتأمين رزقه غير الغزو وقتل الآخر أو نفيه وطرده عمدا:

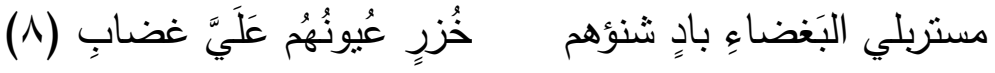

لقد فرضت الطبيعة على العربي أن يكون محارباً غازياً، لأنها حرمته من خيرات هذه الدنيا ومن طيبات ما

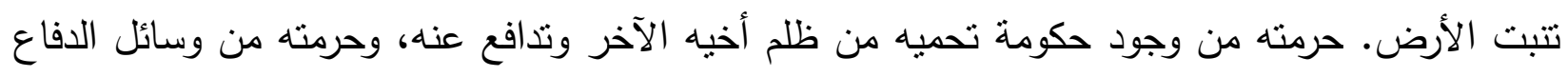
عن النفس ضد الطبيعة القاسية، فجعلته لا يملك شيئًا يكنّ إليه في البوادي ليحمي نفسه من التهن الرياح السموم

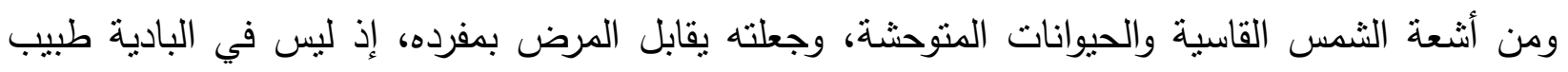

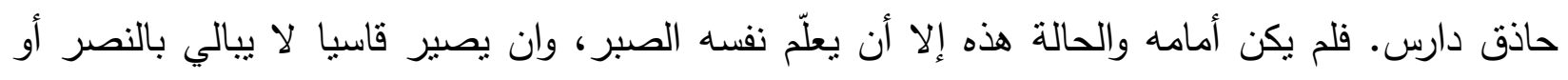

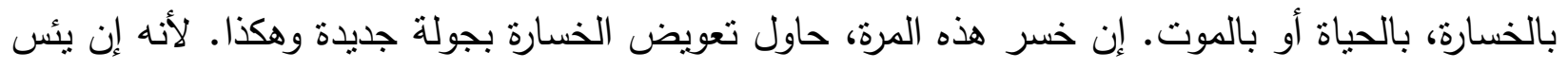

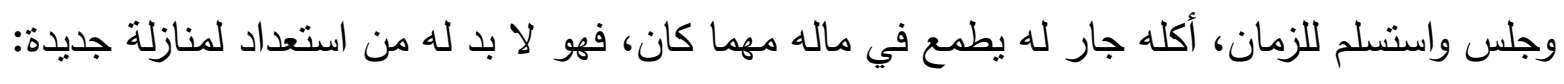

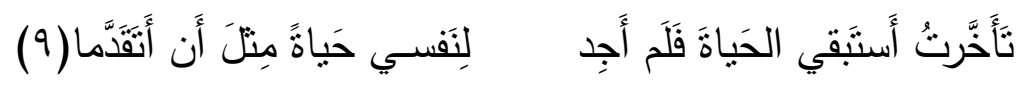


لذا عاش العرب قبل الإسلام حباة قائمة على التدافع، وأحاطت بهم أسباب الموت من كل جانب، وأمسى تمجيد القوة شعار الناس: فكانت البيئة واحدا من أهم أسباب نوارث الخصومات والخلافات بين الأفراد، وتكاد سمة ذلك المجتمع تتطبق على سمة ما يقال في عالم السياسة اليوم بعدم وجود صديق دائم ولا عدو دائم . فهم إن تصالحوا تحالفوا ضد عدو وسالت دماء بعضهم دفاعا عن حليفهم، وإذا اختلفوا تقاتلوا ووقعت بينهم

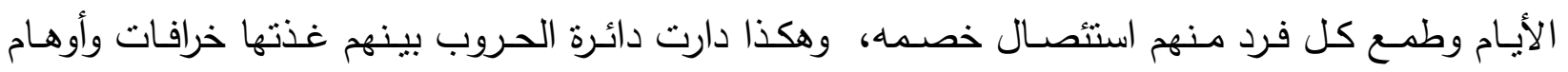
وحكايات منوارثة لا تبيح لهم بالتسامح، وكانت خرافة الهامة والصدى معتتقة بينهم بشدة :

$$
\text { با عمرو إن لا تدع شتمي ومنقصتي أهجوك حتى تقول الهامة اسقوني(· ( ) }
$$

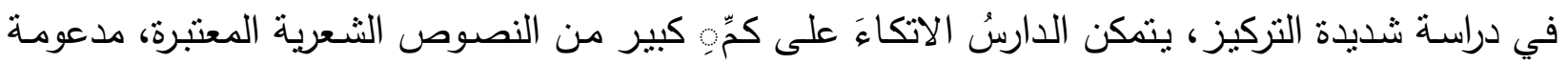

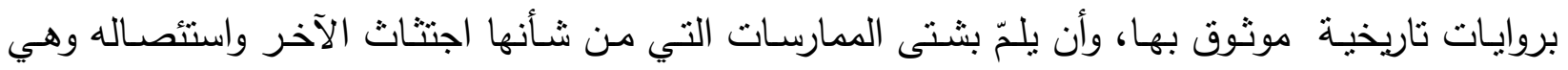

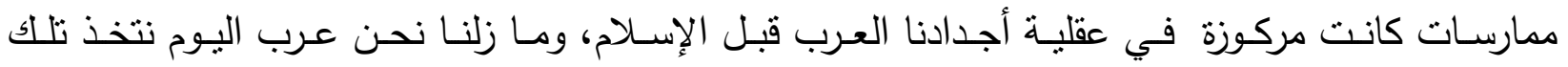

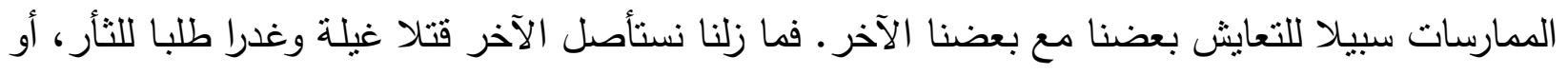

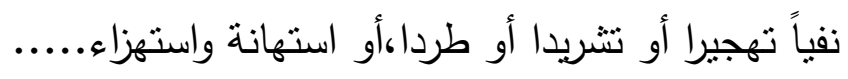

\section{الإقصاء قتتلاً:}

أغنتـا مصسادر التاريخ بأخبار مواقف يأبى فيها أجدادنا الركون إلى التفاهم أو التسامح أو أي سبيل

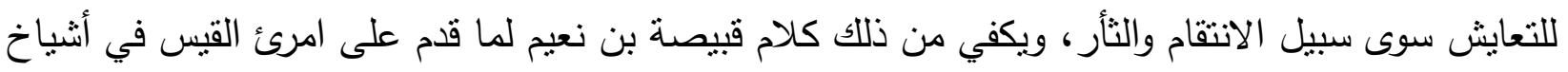

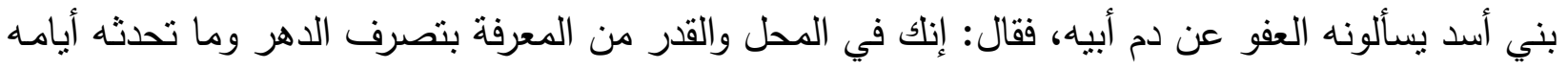

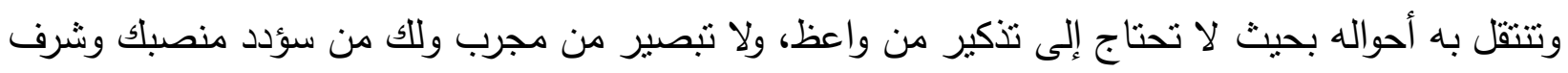
أعراقك وكرم أصلك في العرب محتد يحتمل ما حمل عليه من إقالة العثرة ورجوع عن الهفوة، ولا تتجاوز

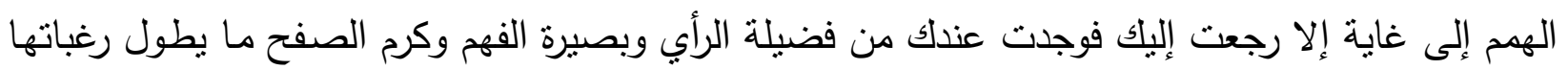

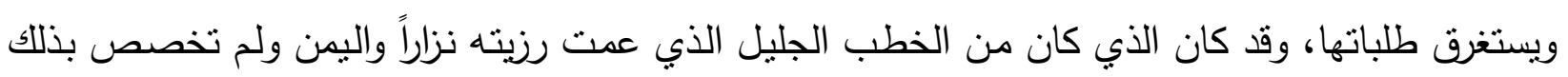

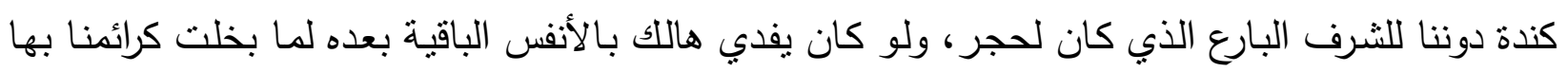

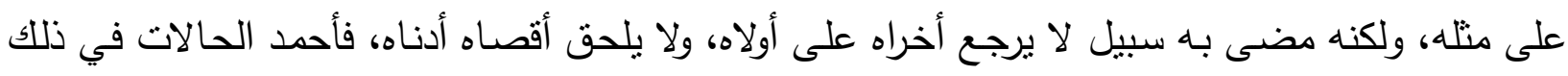
أن تعرف الواجب عليك في إحدى خلال ثلاث: إما أن اخترت من بني أسد أثنرفها بيتاً، وأعلاها في بناء أهاء المكرمات صوتاً، فقدناه إليك بنسعةٍ تذهب شفرات حسامك بباقي قصرته، فنقول: رجل امتحن بها للك عزيز

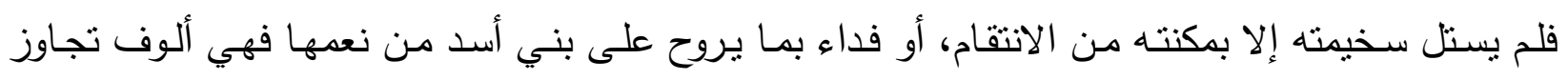

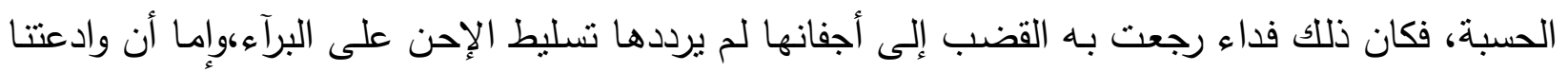


إلى أن تضـع الحوال، فتسدل الأزر، وتعقد الخمر فوق الرايات، قال: فبكى سـاعة ثم رفع رأسـه فقال: لقد

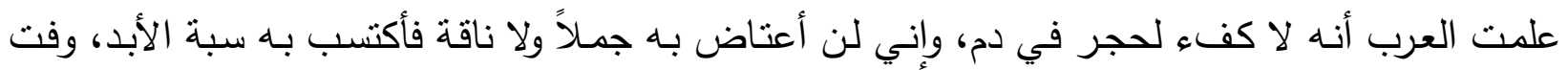
العضد، وأما النظرة فقد أوجبتها الأجنة في بطون أمهاتها، ولن أكون لعطبها سبباً، وستعرفون طلائع كندة واعنة من بعد ذلك تحمل في القلوب حنقاً،وفوق الأسنة علقاً:

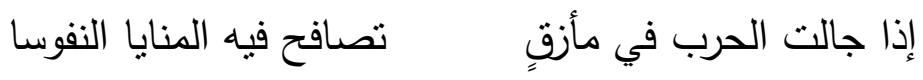

أنقيمون أم تتصرفون؟ قالوا: بل نتصرف بأسوأ الاختيار ، وأبلى الاجترار ، بمكروه وأذية وحرب وبلية ثم نهضوا

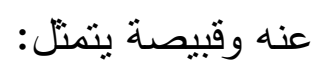

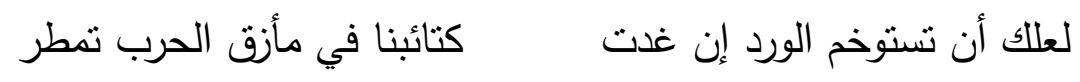

فقال امرؤ القيس: لا والله، ولكن أستعذبه فرويداً ينفرج للك دجاها عن فرسان كندة وكتائب حمير، ولقد

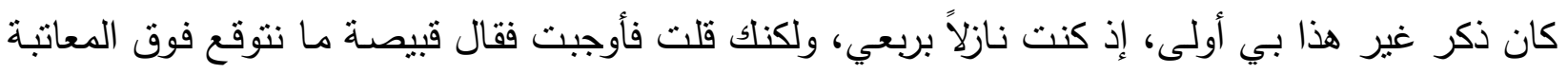
والإعتاب، فقال امرؤ القيس هو ذاكئ(1) (1).

وإننا لو أمعنا النظر في الحوار الجاري بين الرجلين لوجدنا أن قبيصة كان في موقف الاعتذار وقدم

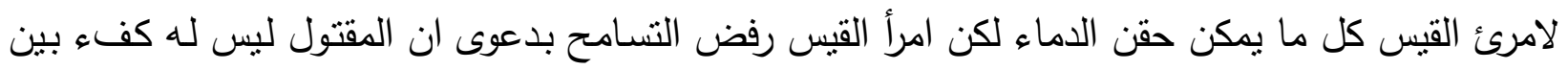

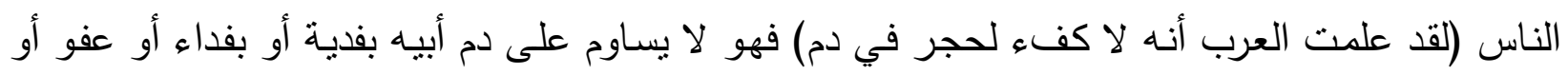

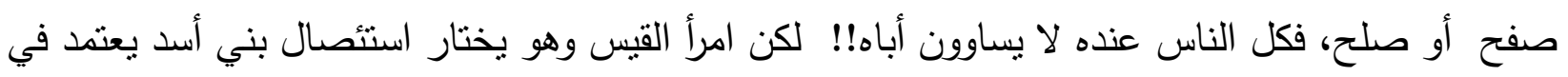

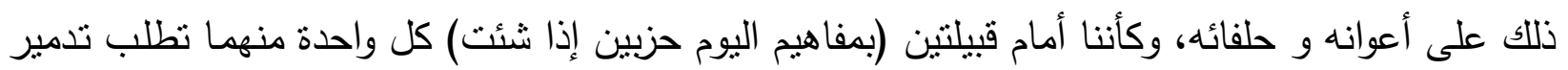
الأخرى قتلا وسبيا وتشريدا، وبذا فالأمر لم يكن شخصيا، بل تعداه إلى العقل العلى المجتمعي. بمعنى: أن الثأر

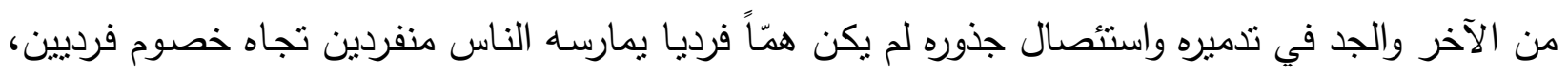
بل تعداه ليكون هما تمارسه الجماعة تجاه جماعة أخرى.

ولم تتوقف موجة استئصال الآخر وقتله على الكبار حسب،بل نالت الأطفال أيضـا، إذ ورد إلينا نص : نص

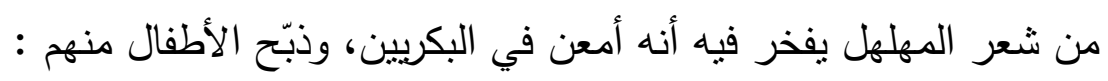
وقهرنا كماتهم بالنضال قد ذبحنا الأطفال من آل بكر

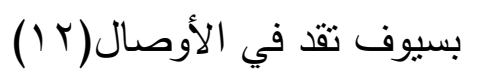
وكررنا عليهم وانثتينا 
ثم أن المهاكل في هذا الموقف لا يتوقف عند اقتلاع خصومه من الرجال الكبار ، ولا عند ذبح الأطفال، بل

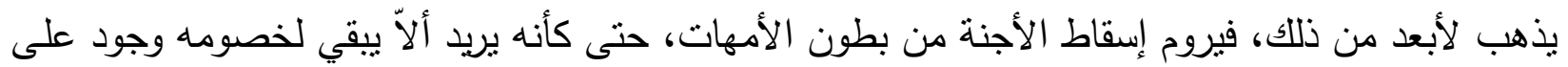

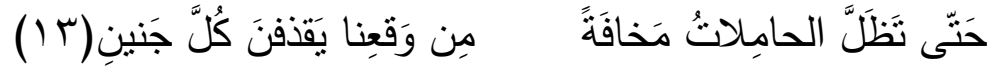

ومن هذا الموقف يمكننا تفهّم عمق الحقد والكراهية للآخر (وهو هنـا ابن العم فمـا بالك إذا كان الخصـ

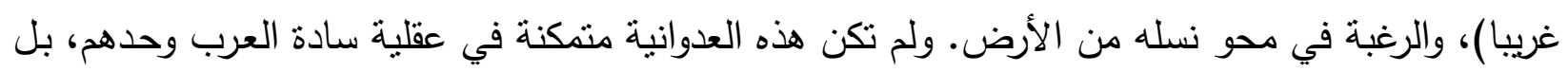

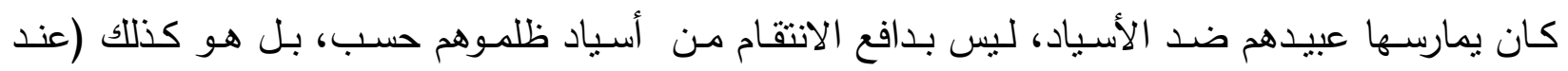

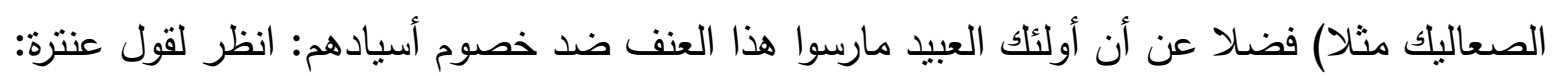

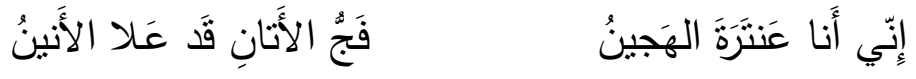

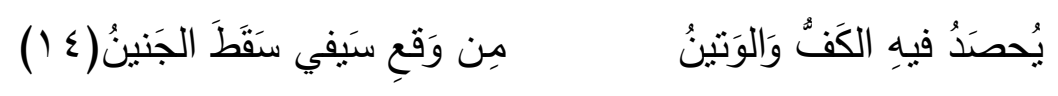

ومما لاشك فيه أن الأحقاد المنبادلة بين أجدادنا الموغلين في القدم؛ جماعات وأفراد، كان يغذي الأجيال جيلا بعد جيل:

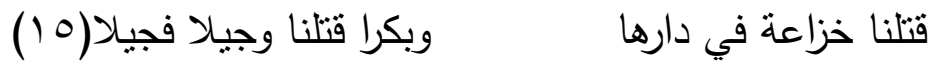

$$
\begin{aligned}
& \text { وَرَكوبٍ تَعزَفُْ الجِنُ بِهِ }
\end{aligned}
$$

لكننا لو توخينا الإنصاف ونحن نراجع مكونات عقلية أسلافنا فعلينا أن ندرك أن مجمل الظروف المحيطة بحياتهم وبتاريخ كل فرد منهم وبكل جماعة منهم (قبيلة) فرضت عليهم هذا السلوك، وأجبرتهم على إزاحة

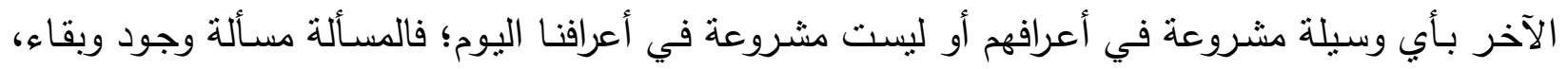

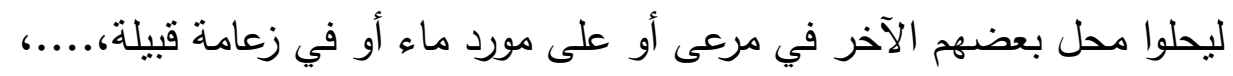


أن خطة هذه الدراسـة لا تأتي على الأسباب الفكريـة والنفسية والاجتماعية والبيئية التي غرست هذه

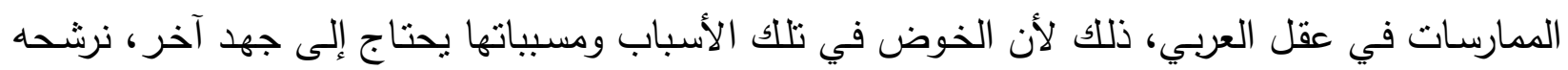
لدراسة أكاديمية متخصصة ما أمكن.

والظاهر أن الأمر لم يك مقتصرا على العرب من أهل البادية، إذ شملت ممارسات العنف والثقتيل أهل

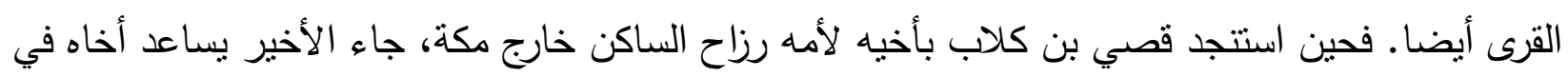
استبعاد بعض أهل مكة الأصليين قتلا:

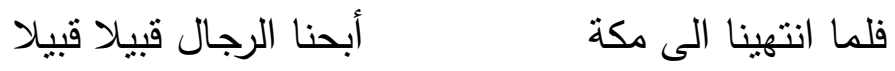

$$
\begin{aligned}
& \text { نعاورهم ثم حد السيوف وفي كل أوب خلسنا العقولا }
\end{aligned}
$$

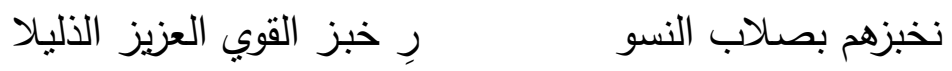

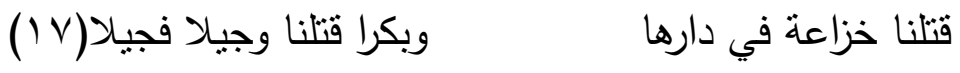

ولما وقعت الحرب بين جديلة والغوث الطائين كان أبو الطحان القيني مجاوراً في جديلة من طيء، وكانت

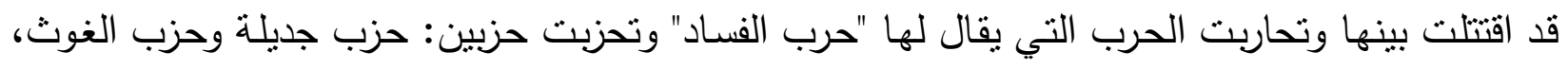

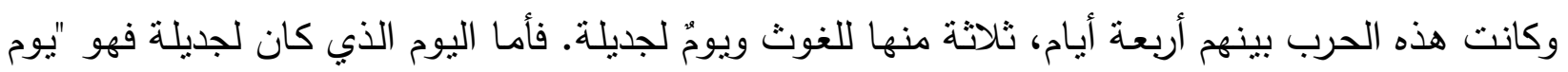

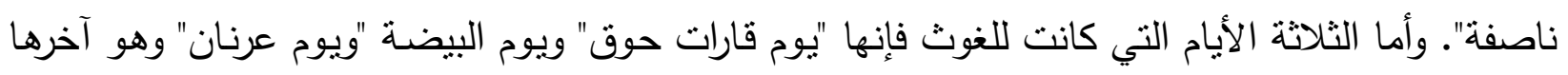

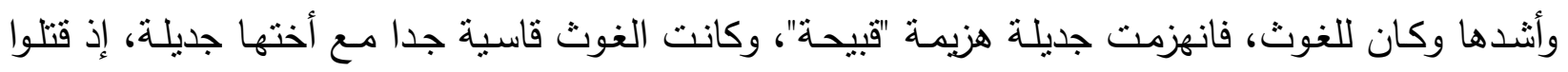

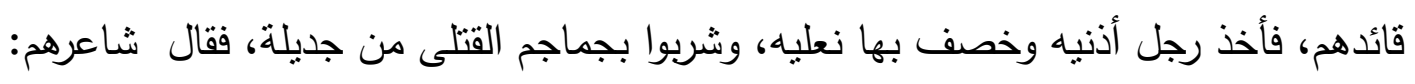
ونخصف بالآذان منكم نعالنا ونشرب كرها منكم بالجماجم(1)

فأي فعل قاسٍ يمكن أن يكون أنثد عنفاً، وأكثر قسوة، من قيام الإنسان بتقطيع أعضاء القتلى والتثثيل بها

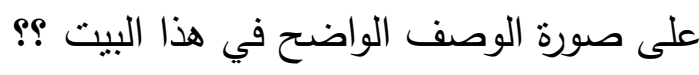
الإقصاء نفياً وطرداً وتشريداً نقول: نفيت الرَجلّ وغَيَهَ نَفْياً إذا طردتَه، فهو منفيّ، قال الله تعالى: "أو يُنْفَوْا من الأرض". والانتفاء من

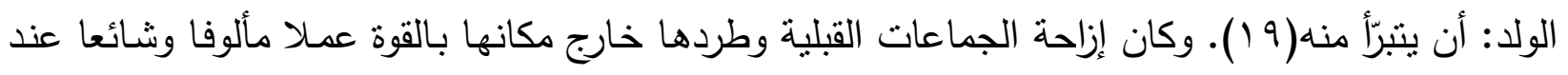


العرب، فرزاح النهدي ساند أخاه قصيا بن كلاب على نفي سكان مكة من مواقعهم، وحلوا محلهم(· ) )، فقال قائلهم:

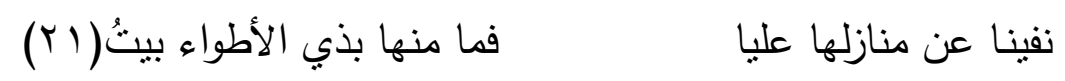
وقال:

كما لا يحلون أرضا سهولا

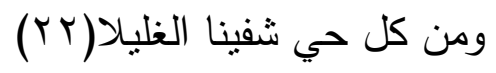

نفينا هم من بلاد المليك فأصبح سبيهم في الحديد

وكان نفي الأفراد من القبيلة وطردهم من الأسرة ممارسة منتشرة، قد يأتي نتيجة جريرة يرتكبها الفرد، تضر بالقبيلة أو بالأسرة أو بسواهما.

وكان امرؤ القيس طرده أبوه لما صنع في الثـعر بفاطمة ما صنع، وكان له عاثشقا، فطلبها زماناً فلم

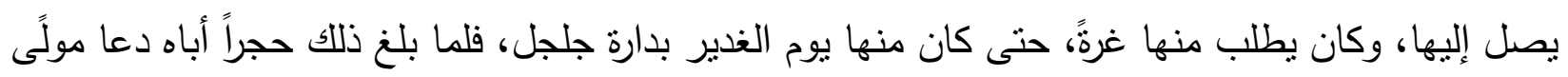

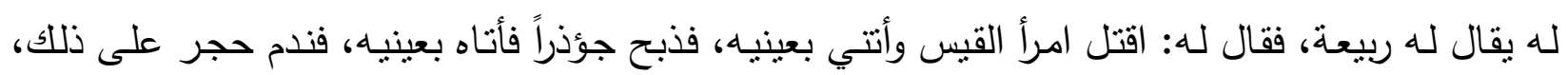

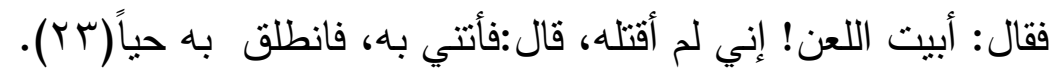
وتجد للنفي صورا متعددة في ممارسات الجاهليين بعضهم ضد البعض الآخر ، فقد يرد من المجاز أن يقال: فلان من نفايات القوم ونِفاهم. قال الثاعر : عشيرتك الأدنون خير عشيرة وأنت دنيّ من نفيَ القوم راضع(؟) بمعنى أنك من أراذلهم، وأنت لا تقع في المنزلة السوية منهم، فكانتك النفي من شمائل قومك الكريمة. وقد

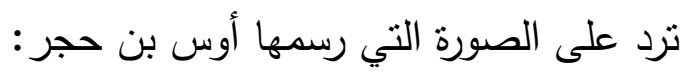
دَحَقَت فَخَرَّقَ ثَفَهرا الزَنْدُ

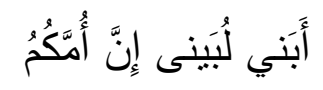
تَتَفي المَطارِقُ ما يَلِي القَرَدُ (Yo) تُنَفَونَ عَن طُرُقِ الكِراجِ كَما 
يطمح أوس لأن يكون نفي خصمه قلعا من الجذور ، لا تتبت بعدها، بمعنى أن النفي الذي يتمناه لخصمه،

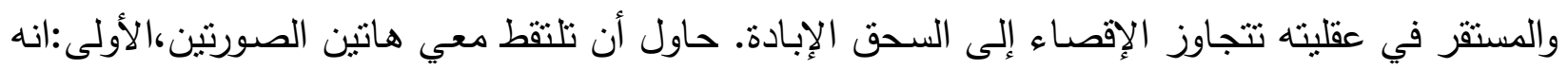
يشبه خصمه بالصوف والوبر المنساقط تلقائيا من جسم نعجة أو ناقة،( والصوف والوبر المنساقط في هذه الإنهاء

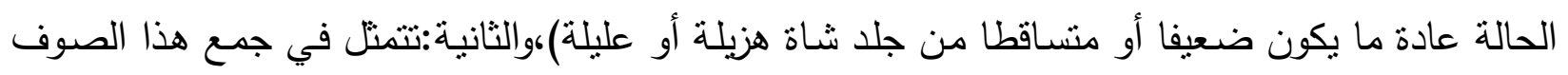

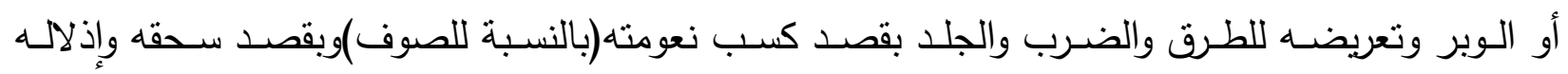
وترويضه وأهانته (بالنسبة للخصم).

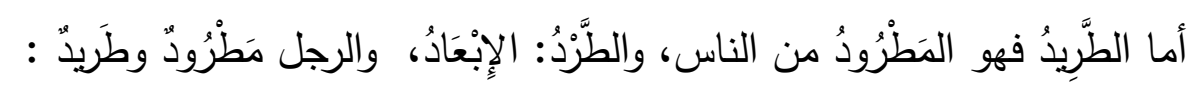

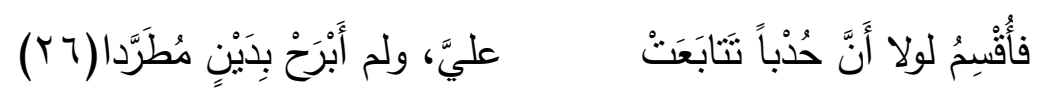

ومن المؤكد أن من يتعرض للإقصاء بالطرد أو بسواه من من ممارسات التهميش بشعر بكثبر من المرارة

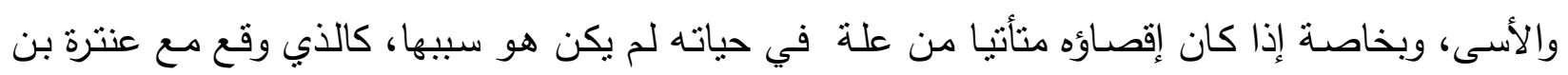
شداد:

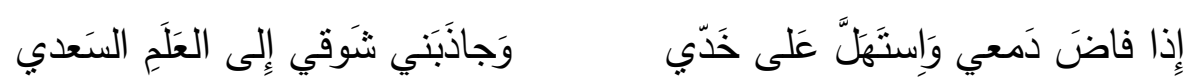

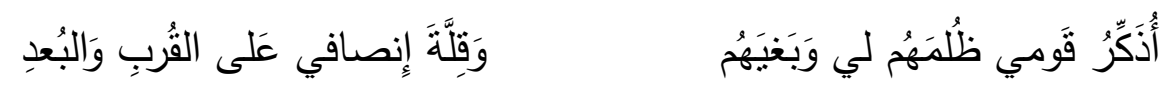

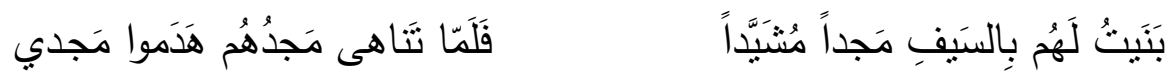

$$
\begin{aligned}
& \text { يَعيبونَ لَوني بِالسنوادِ وَإِنَّا }
\end{aligned}
$$

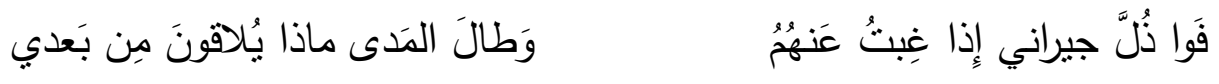

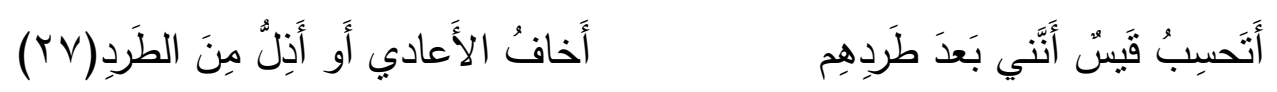

واحتفظت ذاكرة الجاهليين بكثير من ممارسات الطرد والنفي التي وقعت بين قبائل العرب، وظلت أخبارها ماتلة فيما يتتاقله الناس جيلا بعد جيل، ووقف الشعراء الجاهليون يتمثلون ببعض نئ نلك الأخبار :

$$
\text { ولا ثُلاقِي كَما لَاقَتْ بَنو أَسَدِ }
$$




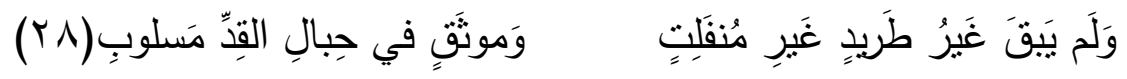

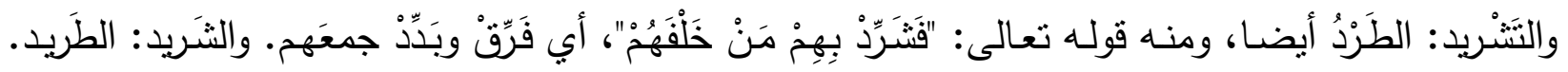
وقول الله عز وجل: "شرّد بهم من خلفهم"، أي: نكَّل بهم، قال:

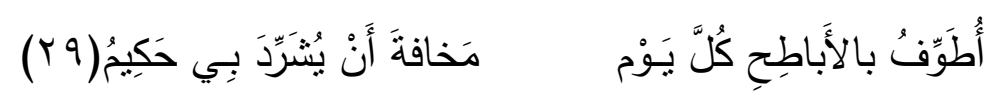

ووجدنا في الثـعر الجاهلي شكلا آخر من أنشكال التشريد، بل سببا آخر من أسبابه، فقد يشهِرٍ فرد

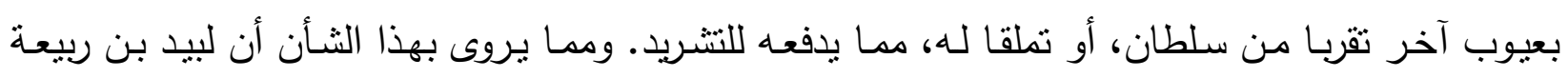

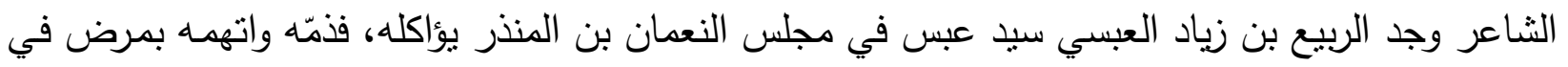

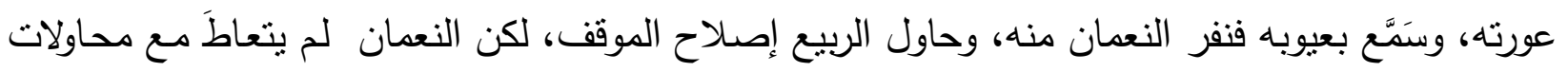

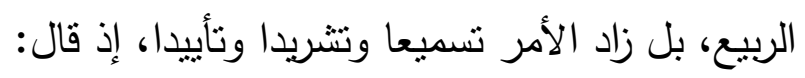

شرّد برحلك عنّي حيث شئت ولا تكثر عليّ ودع عنلك الأقاويلا

فقد رميت بداءٍ لست غاسله ما جاور السيّل أهل الثنّام والنّيلا

قد قيل ذلك إن حقا وان كذبا فما اعتذارك من شيء إذا قيلا(·r)

ولا سبيل لتكرار قصة طرفة بن العبد مع أبناء عمومته، وهم الذين شردوه من صفوفهم، واغتصبوا إرث والده

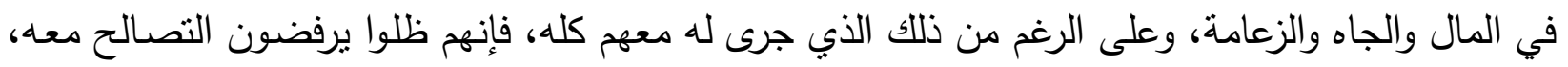

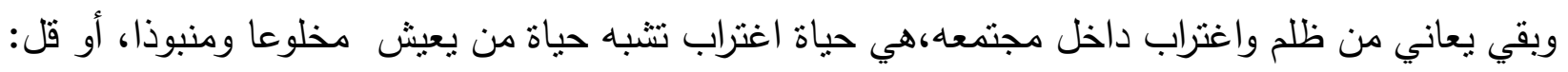
هو الظلم والطرد والخلع والتشريد كله، وهو القائل:

وَأُفردِتُ إِفرادَ البَعبرِ المُعَبَّب

منتى أَدْنُ منهُ يَنْاَ عَني ويَبْعُدِ؟

كما لامتني في الحَيِّ قُرْطُ بنُ معنَِ
إلىى أَن نَحامَتنتي العَشِيرةُ كُلُّها

فَما لي أراني وابنَ عَمَيَ مالِكاً،

يَلُؤمُ وما أدري عَلامَ يَلْومُني، 
كأَنَّا وَضَعَناهُ إلىى رَسْسِ مُلْحَدِ

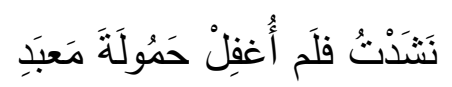

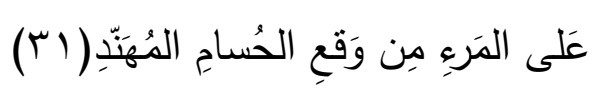

وَأَيَأَسنَي مِنْ كلِّ خَرِ طَلَبتُهُ،

على غَبرِ ذَنْبِ قُلْتُهُ غَيرَ أَنَّني

وَظُلُْ ذَوبي القُربى أَثَنَدُ مَضاضَنَة

الإقصاء بالاستهانة والاستهزاء

وما كان إقصاء الآخر بأسلوب الاستهانة أو الاستهزاء ببعيد عن عقلية العرب، ولم يأت في سلوكهم

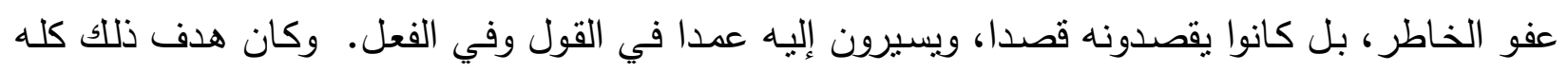
إقصاء الآخر ، وتدمير سمعته وجاهه ووجاهته، وضربه في موضع الوجع الحقيقي:

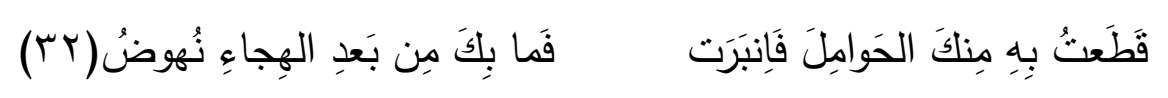

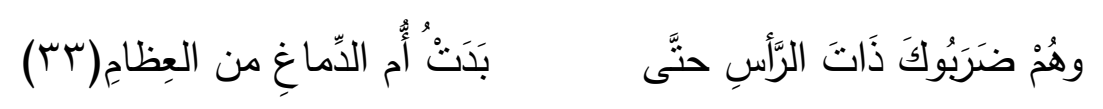

وفي طرف من هذا يأتي التقليل من شأن الآخر، وبث صور الاستهزاء بمكانته، حتى يحو لبعضهم زحزحة

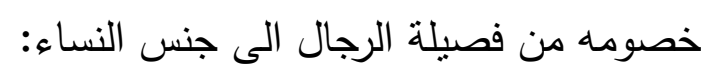

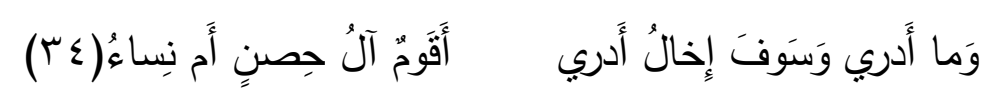

وبمثل هذا المضمون، تنسابقن الثواعر الجاهليات وتزاحمن على تعيير رجال قبائلهن إذا تباطأوا في أخذ

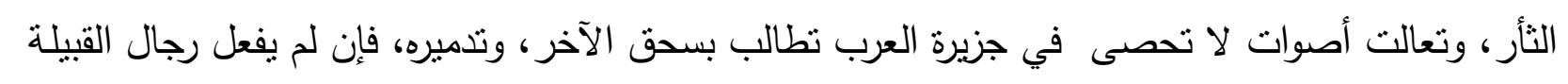

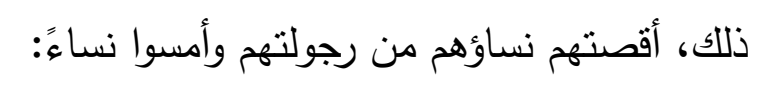

$$
\begin{aligned}
& \text { فَكونوا نساءً لا نعبّ من الكحلِ } \\
& \text { وَإِن أننتُ لَم تغضبوا بعدَ هذِه } \\
& \text { خُلقتم لأثوابٍ العروس وللنسلِ } \\
& \text { وَيَخال يَشُشي بيننا مشية الفحلِ(ro) } \\
& \text { وَدونكمُ طيب العروسِ فإنّما } \\
& \text { فَبُعداً وسُحقاً للّّي ليس دافعاً }
\end{aligned}
$$

الإقصاء تهميشاً وتشويهاً 
وقد يأتي الإقصاء في شكل من أشكال التشويه._والتشويه: يعني التقبيح، ومنه المشوّه. والثََّوَه من قولهم:

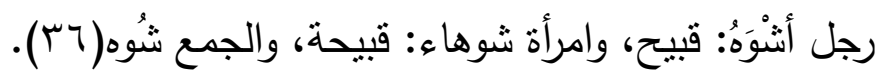

وتتعدد صور تشويه الآخر في الثنعر الجاهلي، وتكاد مهمة غرض الهجاء في ذللك العصر تكون قائمة

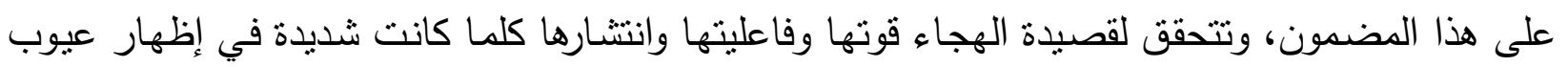

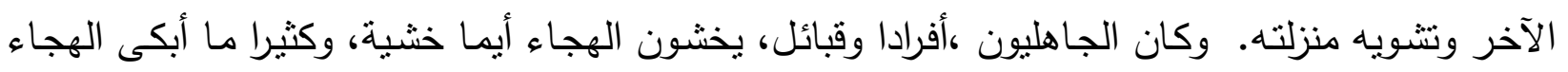
زعماء القوم وساداتهم.

يروى أن الأعثى أنى علقمة بن علاثة فقال له: أجرني، فقال: قد أجرتك. قال: من الجن والإنس؟ قال نعم.

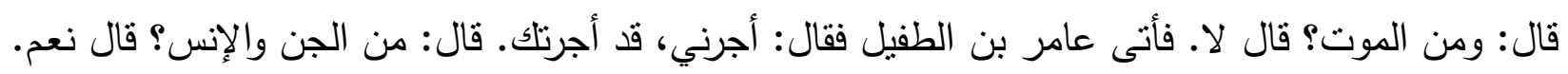
قال: ومن الموت؟ قال نعم. قال: وكيف تجيرني من الموت؟ قال: إن مت وأنت في جواري بعثت إلى أهلى أهلك الدية. فقال: الآن علمت أنك قد أجرتتي من الموت. فمدح عامراً وهجا علقمة بقوله: تبيتون في المشتى ملاءً بطونكم وجاراتكم غرثى يبتن خمائصـا ويروى أن علقمة لما سمع هذا البيت، بكى وقال: اللهم أجزه وأخزه إن كان كاذبا(rا) وصور تسقيط الآخر وتهميشه متعددة وأساليب تمريرها متتوعة، فتارة يميل أجدادنا إلى إقصاء الآخر عن طريق التشهير بالأعراض: ونئ

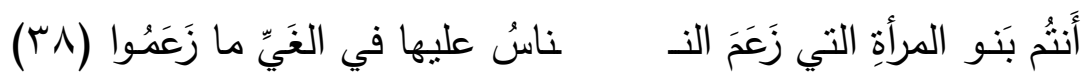
وتارة بشتمه، وإلصاق صفة اللؤم به وبآبائه، وبأبنائه:

$$
\begin{aligned}
& \text { وَاللُؤُمُ أَكَرَج مِن وَبَرِ وَما وَلَدَا } \\
& \text { اللَؤمُ أَكَرَجُ مِن وَبرٍ وَوالْدَدُ }
\end{aligned}
$$

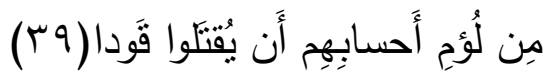

$$
\text { قَوَمُ ما جَنى جانيهُمُ أَمِنوا }
$$

ويضيق المقام هنا في عرض أساليب تسقيط الآخر وتهميشه،والتشهير به بقصد الإقصاء، ذلك لأنها من الوفرة والكثرة بسعة تكاد نتمل معظم الموروث الثعري الجاهلي، فحين يهجو فانه يشتم، وحين يفخر ، فإنها يتعالى ويرفع مقام نفسه فوق مقام الآخرين:

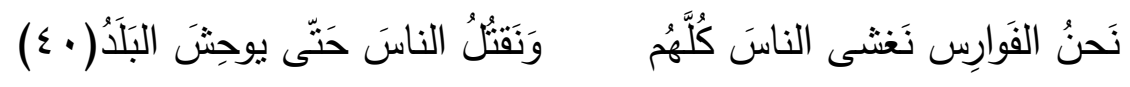


فالحارث بن عباد على استعداد تام لمحو الجنس البشري كله من فوق سطح الأرض كي يبقى هو وقبيلته

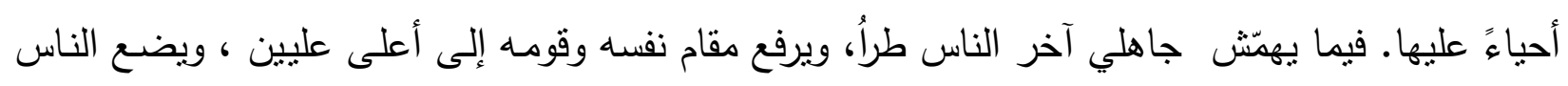
كلهم في أسفل سافلين:

مَجداً دَعائِيُهُ مِن نَحنِهِ زُلْقُُ

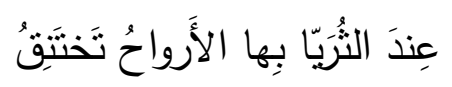

وَلا يَكونُ لِبابٍ دونَنا غَلَقُ

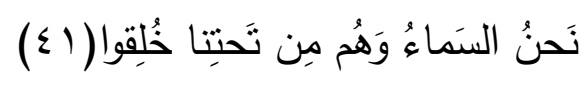

بَنَى لَنَا أَوَّلونا فَوقَ عالِيَةٍ

$$
\text { حَتِى إِستَوَينا عَلى أَثْرافِ رابِيَةٍ }
$$

$$
\text { لا يَقَتح الناسُ باباً حينَ نَغلقِقُُ }
$$

$$
\text { (جعال بن عبد النهمي/ الاكليل/ الهمداني }
$$

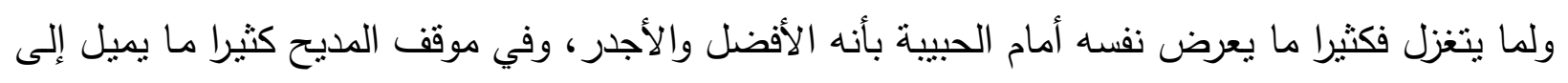
التعريض بخصوم الممدوح فيرفع شأن مددوحه ، ويقلل من شأن آخرين، انظر لقول النابغة: فإنك شمس والملوك كواكب إذا طلعت لم يبد منهن كوكب(ץ)

وفي غرض الرثاء، يكون ميّتُه أفضل الأموات، وقاتلوه جبناء، أو بخلاء، أو غادرين....... وقل مثل هذه الأقوال في كمّ غير قليل من مضامين القصيدة الجاهلية، وأغراضها.

\section{الإقصاء تعالياً على الآخر وتمايزاً وتباهياً}

تتجه مضامين قصيدة الفخر لإظهار التفوق على الآخر ، وإظهار الانفراد بالتميز عليه، وذلك كله يأني في

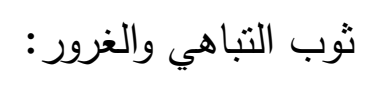

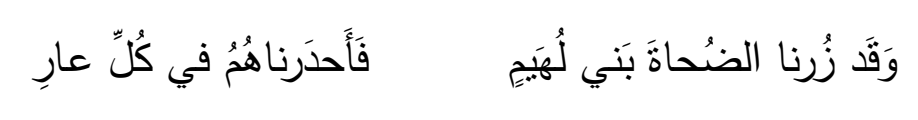

فَقُل لِابنِ الذُعَبرِ النَّلِ هَلَّا

البراق، في هذا الموقف، أقصى خصومه (الجماعـة: بني لهيم) وأبعدهم من كل خصيصـة تمت للتبـاهي

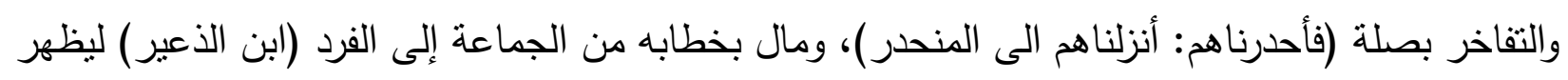

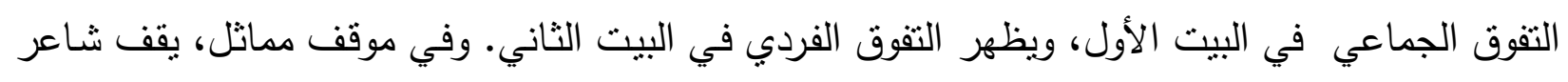


فارس آخر يفاخر الناس كلهم ويتباهى عليهم دونما استثناء، ليقول لهم: نحن نشرفكم، بل أن ملابسنا تشرف

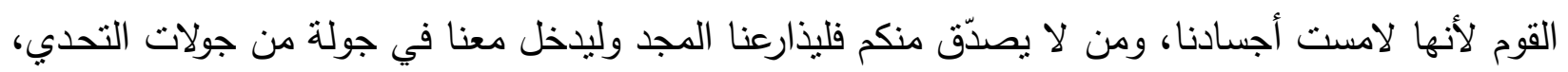

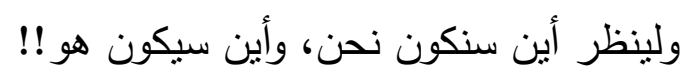

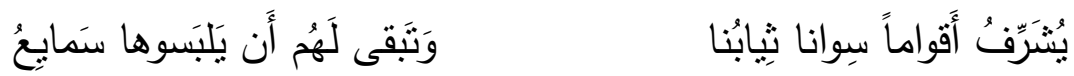

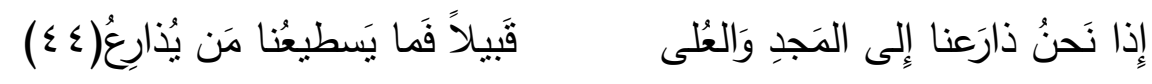

وكان نقص الماء في بيئة الجزيرة، واحدا من مبررات شجعت على إقصاء الآخر وطرده كلما سمحت القوة

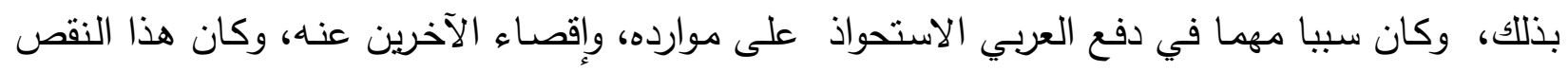

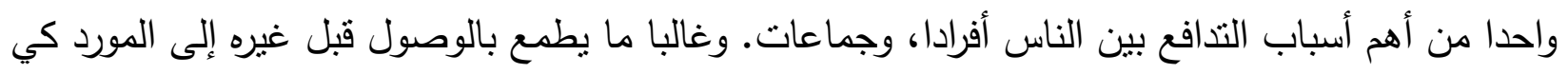

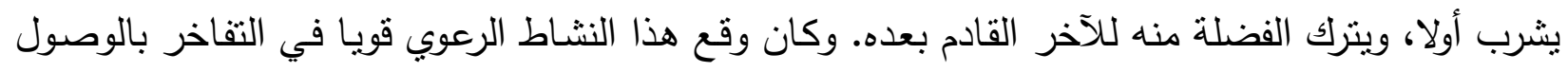
إلى الماء أولا، والتباهي بإقصاء الآخر عنهاء، واقرأ هاهنا أقوال شعرائهر:

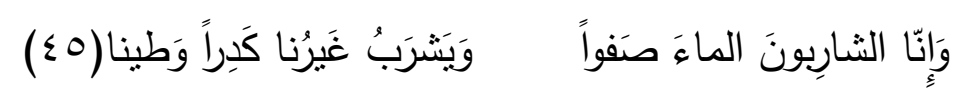

وعمرو بن كلثوم لا يكتفي بالثربة الأولى حسب، ولا يكتفي بنفي الآخرين عن أي مورد من موارد الماء، بل

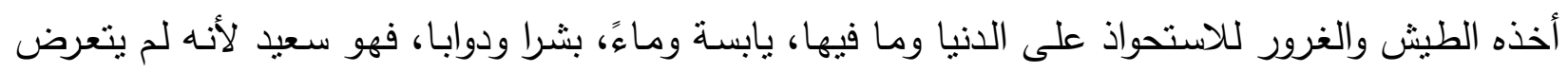

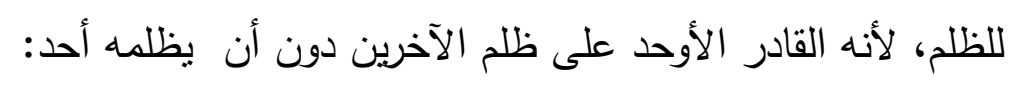
وَيَتَرَبُ غَيُرنا كَدَراً وطينا
وَنَشرَبُ إِن وَرَدنا الماءَ صَفقاً
وَنَبطُِ حينَ نَبطُُِ قِادِرينا
لنا الدُنيا وَمَن أَضحى عَلَيها

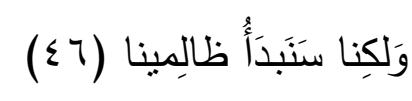
نُسَتّى ظالمِمينَ وَما ظُلِمنا

الهوامش والتعليقات

1. الصحاح (باب ق ص 1). 


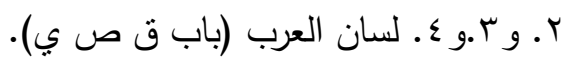

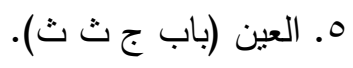

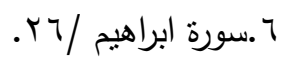

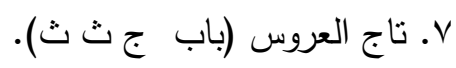

$$
\begin{aligned}
& \text { ^ـ الثعر والثعراء، البيت لعباد بن عمرو بن كلثوم. }
\end{aligned}
$$

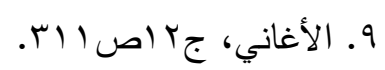

$$
\begin{aligned}
& \text { • } 1 \text {. صبح الأعشى في صناعة الانشا،ج اص الح؛ والبيت للإصبع العدواني. }
\end{aligned}
$$

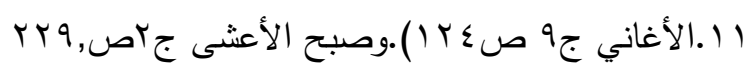

$$
\begin{aligned}
& \text { r ا ـ ديوان مهلهل بن ربيعة،صرم. }
\end{aligned}
$$

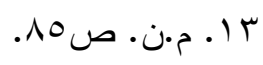

$$
\begin{aligned}
& \text { ع ( اديوان عنترة، ص,س } \\
& \text { 1 الأغاني جهص آـ. والبيت لرزاح النهدي. } \\
& \text { T } 1 \text { ـ ديوان طرفة بن العبد، ص,r؟ } \\
& \text { V ا. الأغاني جهص آج. والبيت لرزاح النهدي. } \\
& \text { 1 ا. الأغاني جr (ص,ء؛ } \\
& 9 \text { 1 ـ العين ( باب ن ف ي). }
\end{aligned}
$$

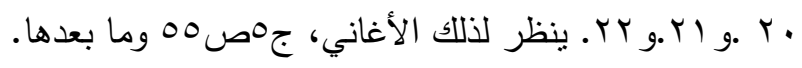$$
\text { rז. وردت القصة في الشعر والشعراء،به. }
$$$$
\text { ع r. أساس البلاغة ( باب ن ف ي). }
$$

O Y. ديوان أوس بن حجر،ص ا ـ ـ r. دحقت: خرج رحمها بعد الولادة. الثقر : حياء المرأة. التزنيد: أن تُخَلّ أثناعر الناقة

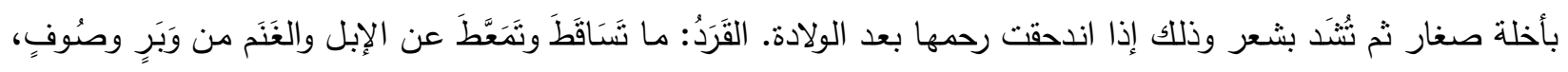

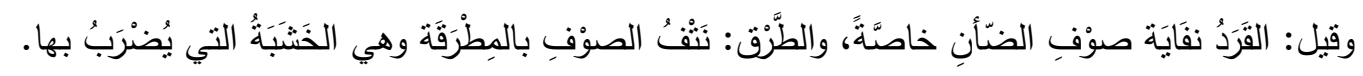




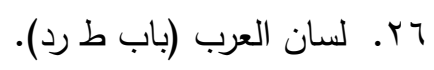

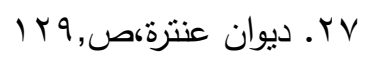

^r ب. ديوان النابغة الذبياني، ص,rه

q. الصحاح (باب ش رد) ولسان العرب (باب ش ر د). وحَكِيمٌ: رجل من بني سُلَيَم كانت قريش ولته الأَخذ على أيدي

السفهاء.

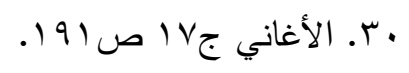

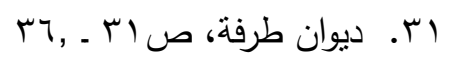

r - (ب. ديوان عبيد بن الأبرص، ص.9.

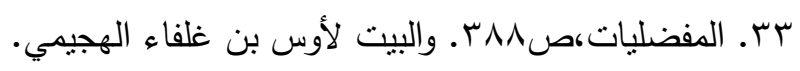

ع ז. شعر زهير بن أبي سلمى،ص

هr. الأغاني ج ا (ص • V . ـ والبيت لعفيرة بنت عباد الجديسية.

$$
\text { דr. صحاح اللغة (باب ش و هـ). }
$$

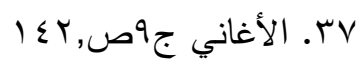

م r. المفضليات،ص rعء. والبيت للجميح الأسدي.

9 r. كتاب الصناعتين، ص و9.

• ع. ديوان الحارث بن حلزة .ص99. البيت للحارث بن عباد.

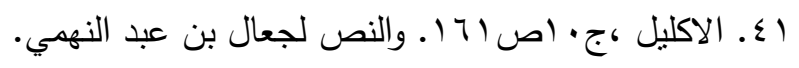

r

بــ البرّاق بن روحان بن أسد بن بكر بن مرة، من بني ربيعة. شاعر جاهلي من أهل اليمن ومن شعراء الطبقة الثانية وشهرته

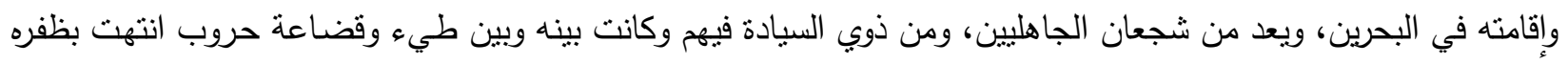
وظهور قومه، وهو من أقارب المهلهل وكُليب.

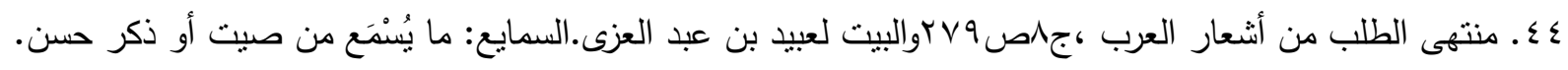


0ـ ـ شرح ديوان أمية بن الصلت،ص4م.

Tــ. ديوان عمرو بن كلثوم،ص • V.

$\underline{\underline{د}}$

القران الكريم

1. أساس البلاغة، الزمخشري(تم/هـه) نحقيق محمد باسا عيون السود، دار الكتب العلمية، بيروت، 991 (م. r. الأغاني أبي الفرج الأصفهاني، تحقيق سمير جابر ، دار الفكر، بيروت(د.ت).

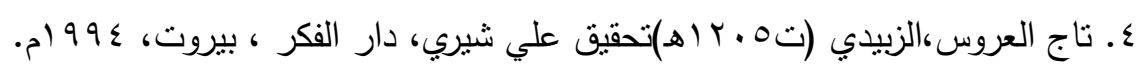
ه.ديوان أوس بن حجر، تحقيق محمد يوسف نجم، دار صادر بيروت، 9 ام. 7. ديوان الحارث بن حلزة، إعداد طلال حرب، الدار العالمية، بيروت، ج9 (م.ص,99 99

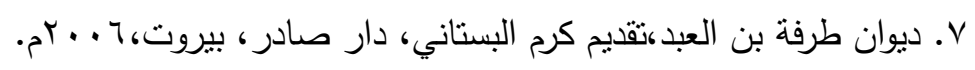
^. ديوان عبيد بن الأبرص، ص.9. عبيد بن الأبرص،دار صادر، بيروت، 911 ام. 9.ديوان عمرو بن كلثوم،دار صادر، بيروت، ع . بام.

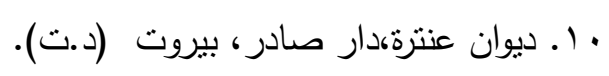
1)

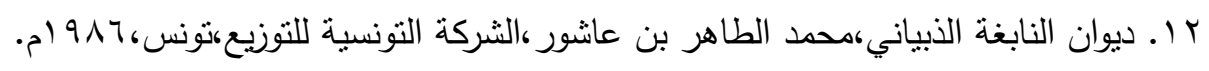
r ا ـ شرح ديوان أمية بن الصلت،سيف الدين الكاتب،دار الحياة، بيروت(د.ت) ـ ا. شعر زهير بن أبي سلمى،صنعة الأعلم الثنتمري(ت هـ)،تحقيق فخر الدين قباوة،دار الكتب العلية، بيروت، بو9 ام.

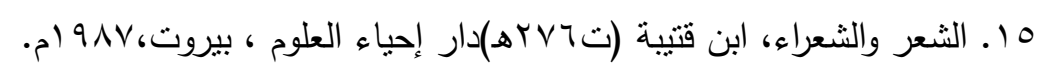

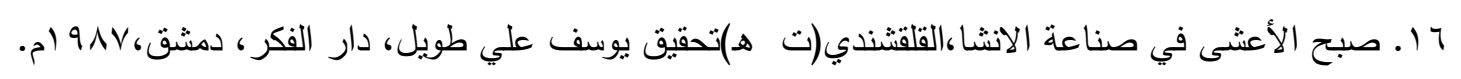
V V ا. الصحاح تاج اللغة وصحاح العربية، الجوهري (ت هـ)، تحقيق أحمد عبد الغفور عطار، دار العلم للملايين، القاهرة، . $191 \mathrm{~V}$ 


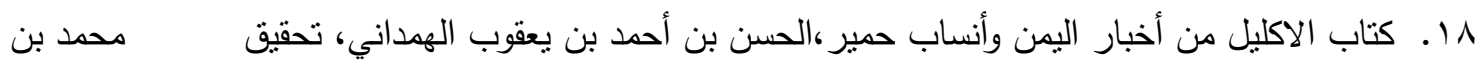

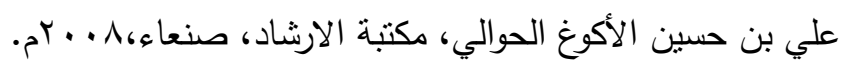

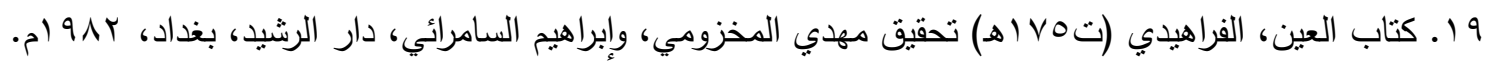
• r. كتاب الصناعتين،تصنيف أبي هلال العسكري(ت هـ)تحقيق علي محمد البجاوي وزميله،المكتبة العصرية،بيروت،

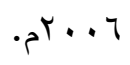

$$
\text { ا r. لسان العرب، ابن منظور (ت ) ضبطه خالد رشيد القاضي، دار صبح،بيروت، } 7 \text { +. rم. }
$$

r r . المفضليات،المفضل الضبي (ت V I هـ) تحقيق أحمد محمد شاكر، وعبد السلام هرون،دار المعارف، مصر ، بـ9 (م. rr. منتهى الطلب من أشعار العرب،محمد بن المبارك، تحقيق محمد نبيل طريفي،دار صادر ، بيروت،م . . rم. 